\title{
Self-reported psychopathology and health- related quality of life in heroin users treated with methadone
}

This article was published in the following Dove Press journal:

Neuropsychiatric Disease and Treatment

21 December 2012

Number of times this article has been viewed

\author{
Ying-Zai Chen' \\ Wei-Lieh Huang ${ }^{1,2,5}$ \\ Jia-Chi Shan ${ }^{4,5}$ \\ Yu-Hsuan Lin ${ }^{1-3,5}$ \\ Hung-Chieh Wu Chang' \\ Li-Ren Chang ${ }^{1,6}$ \\ 'Department of Psychiatry, National \\ Taiwan University Hospital, Yun-Lin \\ Branch, ${ }^{2}$ Institute of Brain Science, \\ National Yang-Ming University, \\ ${ }^{3}$ Sleep Research Center, National \\ Yang-Ming University, ${ }^{4}$ Department of \\ Psychiatry, Cathay General Hospital, \\ Taipei, ${ }^{5}$ Department of Psychiatry, \\ National Taiwan University Hospital, \\ ${ }^{6}$ Department of Psychiatry, Medical \\ College, National Taiwan University, \\ Taipei, Taiwan
}

Background: Health-related quality of life (HRQoL) remains poor among heroin users, even after being treated with methadone. Evidence regarding self-reported psychopathology and HRQoL in heroin users is also limited. The present study aimed to investigate the association between self-reported psychopathology and HRQoL in Asian heroin users treated with methadone.

Methods: Thirty-nine heroin users treated with methadone and 39 healthy controls were recruited. Both groups self-reported on demographic data, the Brief Symptom Rating Scale, EuroQoL-5D, and World Health Organization Questionnaire on Quality of Life: Short Form. We compared clinical characteristics, psychopathology, and HRQoL between the two study groups. Correlation and regression analyses were conducted to explore the association between psychopathology and HRQoL in the heroin user group.

Results: Heroin users had more psychopathology and worse HRQoL than healthy controls. The HRQoL of heroin users had significant correlations with Brief Symptom Rating Scale scores. HRQoL could be predicted by depression, anxiety, paranoia, and additional symptoms (ie, poor appetite and sleep difficulties) independently.

Conclusion: Self-reported psychopathology, depression, anxiety, paranoia, poor appetite, and sleep difficulties had a negative impact on each domain of HRQoL among heroin users treated with methadone. The importance of the environmental domain of HRQoL is discussed. Clinicians should recognize comorbid psychiatric symptoms early on to improve HRQoL in heroin users.

Keywords: heroin abuse, Brief Symptom Rating Scale, World Health Organization questionnaire on quality of life

\section{Introduction}

Heroin abuse is a chronic disease with a high tendency to relapse. ${ }^{1,2}$ It is characterized by comorbid medical illness, increased mortality, coexisting psychiatric diagnoses, and functional impairment. ${ }^{3-5}$ The effectiveness of maintenance treatment using methadone in treating heroin abuse has been validated..$^{6,7}$ Methadone maintenance treatment can reduce heroin use, illicit use of other types of drugs, risky behavior for contracting human immunodeficiency virus, as well as criminal behavior in heroin users. $^{8}$ It can improve both physical and mental health, and reduce mortality. ${ }^{1,6,9}$ On the other hand, there have been adverse events associated with methadone therapy. Lethal cardiac complications, severe constipation, and sexual dysfunction have been reported. It is noteworthy that heroin users treated with methadone have high rates of comorbid psychiatric disease, such as major depression, bipolar disorder, anxiety
Correspondence: Li-Ren Chang Department of Psychiatry, National Taiwan University Hospital, Yun-Lin Branch, 579 Sec 2, Yunlin Rd, Douliu City, Yunlin County 6404I, Taiwan Tel +8865532 39II ext 7106 Fax +886 55337115

Email kasparchang@gmail.com
(C) 2013 Chen et al, publisher and licensee Dove Medical Press Ltd. This is an Open Access article which permits unrestricted noncommercial use, provided the original work is properly cited. 
disorders, schizophrenia, and personality disorders. ${ }^{10}$ There are also contemporary challenges surrounding treatment with methadone. Firstly, daily methadone clinic visits are not convenient for many heroin users and this is a common reason for discontinuing a methadone maintenance treatment program. The "take-home" status actually reduces illicit drug use, ${ }^{11}$ but current evidence shows that multiple days' supply of take-home doses is related to risk of diversion or lethal overdose. ${ }^{12,13}$ Secondly, subjects enrolled in a methadone maintenance treatment program may still continue their problematic heroin or other substance abuse. They feel frustrated concerning major life issues, including poor family interaction, disrupted social relationships, and unemployment. ${ }^{10}$ In brief, the effectiveness of the methadone maintenance treatment program is limited.

Health-related quality of life (HRQoL) provides a valuable outcome measure in heroin users treated with methadone. ${ }^{14}$ Actually, HRQoL can better reflect the relationship between psychiatric symptoms and real daily life among heroin users. ${ }^{15}$ It is well recognized that heroin users have worse HRQoL than the healthy population, and in longitudinal studies, heroin users treated on a methadone maintenance treatment program have poorer HRQoL than the general population. ${ }^{5,15}$ Methadone does not "normalize" the daily lives of heroin users, and underlying problems may be neglected. To increase HRQoL in patients treated with methadone, it is important to be able to identify factors contributing to worse HRQoL in this population. Among heroin abusers treated on a methadone maintenance treatment, comorbid psychopathology, such as mood, anxiety, and personality disorders, have a further negative influence on HRQoL. ${ }^{5}$ Accordingly, it is reasonable to assume that treatment aimed at improving comorbid psychopathology may also improve HRQoL.

With regard to the ascertainment of psychopathology, there are several studies using objective ratings of psychopathology, such as the Brief Psychiatric Rating Scale (BPRS) and Mini International Neuropsychiatric Interview, for psychiatric assessment of heroin users. ${ }^{5,16}$ Carpentier et al measured psychiatric symptoms using the Mini International Neuropsychiatric Interview, Composite International Diagnostic Interview-Substance Abuse Module, and Structured Interview for DSM-IV Personality, and evaluated HRQoL using the EuroQol-5D. They found that HRQoL in heroin users treated with methadone maintenance was poor, and that comorbid psychopathology was an associated factor of significance. ${ }^{5}$ However, self-reported psychological distress may be a better predictor of HRQoL related to psychiatric illness when compared with clinician-rated symptom severity. In a study reported by Lasalvia et al, both clinicianrated and self-rated psychopathology were simultaneously used to predict subjective HRQoL related to a wide range of psychiatric conditions in a community-based mental health service. ${ }^{17}$ They found that self-rated psychopathology, ie, findings on the Symptom Checklist-90-R, rather than clinician-rated psychopathology, ie, results of the BPRS, was strongly correlated with HRQoL. In addition, correlation between measures of psychopathology obtained using these two methods was quite poor. Notably, there are limited data showing a relationship between self-reported psychiatric symptoms and HRQoL in heroin users. ${ }^{18}$

The current study aimed to validate, firstly, whether heroin users, even after being treated with methadone, still have worse HRQoL than healthy controls, and secondly, whether self-reported psychopathology is a contributing factor. We proposed two hypotheses: firstly, heroin users, even those receiving methadone treatment, still have worse HRQoL and more self-reported psychopathology than healthy controls, and secondly, the self-reported psychopathology is associated with reduced HRQoL among heroin users treated with methadone.

\section{Materials and methods \\ Participants}

Thirty-nine heroin users and 39 healthy controls were recruited from advertisements at the methadone treatment clinic in the Department of Psychiatry, National Taiwan University Hospital, Yun-Lin Branch, Taiwan. The study was approved by the research ethics committee of National Taiwan University Hospital, Taiwan. Both groups completed the informed consent forms and questionnaires after we gave comprehensive explanations of this study. The participants in the heroin use group met Diagnostic and Statistical Manual of Mental Disorders, Fourth Edition (DSM-IV-TR) criteria for opioid dependence, which was confirmed by a board-certified psychiatrist (LRC). Using self-administered questionnaires, we collected demographic data (including age, gender, education, marital status, body mass index, tobacco use, alcohol consumption, and physical illness), drug use patterns (onset, duration, last use, and expense of heroin), and methadone use for the two study groups.

\section{Outcome measures BSRS: measure of psychopathology}

The Brief Symptom Rating Scale (BSRS) was translated from the Symptom Checklist-90-R devised by Derogatis and 
revised into a shorter form for widespread use in Taiwan. ${ }^{19,20}$ The BSRS is a self-reported inventory, including 50 items on a five-point Likert scale (0, "not at all"; 1 , "a little bit"; 2, "moderately"; 3, "quite a bit"; 4, "extremely"). The BSRS provides a comprehensive evaluation of 10 symptom dimensions (somatization, obsession, interpersonal sensitivity, depression, anxiety, hostility, phobia, paranoid, psychoticism, and addition symptoms, ie, poor appetite and sleep difficulties), and three global indices (general symptom severity index, positive symptom total number, and positive symptom distress index). General symptom severity index is a mean score of all BSRS items, positive symptom total number means the number of symptoms rated 1-4 points, and the positive symptom distress index represents the total scores divided by positive symptom total number. The BSRS has satisfactory reliability, validity, and internal structure in assessing psychopathology in patient populations. ${ }^{20,21}$

\section{WHOQOL-BREF (TW): measure of HRQoL}

The Taiwanese version of the World Health Organization Quality of Life Short Form [WHOQOL-BREF (TW)] was developed from the WHOQOL-BREF. ${ }^{22}$ The self-administered questionnaire consists of 26 items from WHOQOL-BREF and two culturally sensitive items suggested by the WHOQOL group. It involves multiple aspects of daily life of the individual, and can be categorized into four domains, including physical, psychological, social, and environmental. All items are rated on a five-point Likert scale, ranging from 1 to 5, and the higher the score, the better the quality of life. WHOQOLBREF (TW) has well established reliability and validity in a Taiwanese population of different ages and diseases. ${ }^{23}$

\section{EuroQoL-5D: a measure of HRQoL}

The EuroQol-5D evaluates five dimensions of subjective health status, including mobility, self-care, usual activities, pain/discomfort, and anxiety/depression. Each dimension includes three levels of health problems, scoring from 1-3 points (ie, 1 no health problems; 2 , moderate health problems; 3, extreme health problems). These raw scores are then transformed into an EuroQol-5D time-trade-off index according to a general population survey in the United Kingdom. The time-trade-off value ranges from 0 to 1 , with 1 indicating the highest subjective HRQoL. Meanwhile, participants were also asked to determine their perceived health status using a visual analog scale (VAS) ranging from 1 to 100, where 100 means the best health. The Taiwanese version of EuroQol-5D has been validated as a measure of HRQoL in the general population and patients with mental illness. ${ }^{24,25}$

\section{Statistical methods}

For comparing demographic characteristics between heroin users and healthy controls, independent $t$-tests and Chi-squared tests were used for continuous and categorical variables, respectively. Independent $t$-tests were then used to determine whether self-reported psychopathology and HRQoL differed between these two groups. We conducted Pearson's correlation analyses to explore correlates of HRQoL measures (WHOQOL-BREF domain scores, EuroQol-5D scores), such as demographic data, drug use patterns, and psychopathology, within the heroin user group. Stepwise multiple regression analysis was used to control for potentially confounding factors, which were covariates showing significant correlation $(P$ value $<0.01)$ with HRQoL measures in Pearson's correlations. We treated four domains of WHO-QoL scores and two EuroQol-5D scores as dependent variables and put these covariates into the independent variables. In addition, variables with a variance inflating factor larger than 2.0, which was suggestive of collinearity, were also dropped from the regression models. Statistical tests were carried out using the Statistical Package for Social Sciences version 15.0 for Windows (SPSS Inc, Chicago, IL). Statistical significance was assumed for $P<0.05$ (two-tailed). Values are expressed as the mean \pm standard deviation.

\section{Results}

\section{Demographic data and drug use pattern}

Demographic data and drug use patterns for the participants are summarized in Table 1 . The overall mean age was $36.9 \pm 7.1$ years, $76.9 \%(n=60)$ were male, $87.2 \%(n=68)$ were junior high school and below (in Taiwan, 6 years education of elementary school and 3 years education of junior high school are obligatory for all citizens), 70.5\% $(n=55)$ were unmarried or single, and mean body mass index was $23.4 \pm 3.6 \mathrm{~kg} / \mathrm{m}^{2}$. There was no difference in age, gender, educational level, marital status, or body mass index between the groups. However, heroin users had significantly higher rates of tobacco use, alcohol consumption, total number of comorbid diseases, human immunodeficiency virus positivity, and hepatitis B or C infection.

\section{Self-reported psychopathology and HRQoL}

As shown in Table 2, heroin users had more severe psychopathology ascertained by BSRS, including somatization, hostility, depression, anxiety, phobia, paranoid, and additional symptoms, than healthy controls. Two global 
Table I Characteristics of study population $(n=78)$

\begin{tabular}{|c|c|c|c|c|c|c|}
\hline & \multirow{2}{*}{$\begin{array}{l}\text { All } \\
(n=78)\end{array}$} & \multirow{2}{*}{$\begin{array}{l}\text { Healthy controls } \\
(n=39)\end{array}$} & \multirow{2}{*}{$\begin{array}{l}\text { Heroin users } \\
(n=39)\end{array}$} & \multicolumn{3}{|c|}{ Statistics } \\
\hline & & & & $\chi^{2}$ & $\mathbf{F}$ & $P$ value \\
\hline Age (mean \pm SD) & $32.2 \pm 6.0$ & $31.2 \pm 6.8$ & $33.3 \pm 4.8$ & & 2.638 & 0.106 \\
\hline \multicolumn{7}{|l|}{ Gender, n (\%) } \\
\hline Male & $60(76.9)$ & $27(69.2)$ & $33(84.6)$ & 2.6 & & 0.107 \\
\hline Female & $18(23.1)$ & $12(30.8)$ & $6(15.4)$ & & & \\
\hline \multicolumn{7}{|l|}{ Education (\%) } \\
\hline Senior high school and above & $10(12.8)$ & $3(7.7)$ & $7(17.9)$ & 1.835 & & 0.176 \\
\hline Junior high school and below & $68(87.2)$ & $36(92.3)$ & $32(82.1)$ & & & \\
\hline \multicolumn{7}{|l|}{ Marital status (\%) } \\
\hline Unmarried or single & $55(70.5)$ & $28(71.8)$ & $27(69.2)$ & 0.062 & & 0.804 \\
\hline Married or cohabiting & $23(29.5)$ & II (28.2) & $12(30.8)$ & & & \\
\hline $\mathrm{BMI}, \mathrm{kg} / \mathrm{m}^{2}( \pm \mathrm{SD})$ & $23.4 \pm 3.6$ & $23.8 \pm 3.7$ & $23.0 \pm 3.5$ & & 0.059 & 0.361 \\
\hline Smoker (\%) & $47(60.3)$ & $8(20.5)$ & $39(100.0)$ & 51.447 & & $<0.001$ \\
\hline Drinker (\%) & $12(15.4)$ & $0(0.0)$ & $12(30.8)$ & 14.182 & & $<0.001$ \\
\hline Number of comorbid diseases $( \pm S D)$ & $0.55 \pm 1.0$ & $0.03 \pm 0.2$ & $\mathrm{I} .08 \pm \mathrm{I} . \mathrm{I}$ & & 67.045 & $<0.001$ \\
\hline HIV positivity (\%) & $5(6.4)$ & $0(0.0)$ & $5(12.8)$ & 5.342 & & 0.021 \\
\hline Hepatitis B (\%) & $5(6.4)$ & $0(0.0)$ & $5(12.8)$ & 5.342 & & 0.021 \\
\hline Hepatitis C (\%) & $13(16.7)$ & $0(0.0)$ & $13(33.3)$ & 15.6 & & $<0.001$ \\
\hline Onset of heroin use, years $( \pm S D)$ & & & $24.7 \pm 5.6$ & & & \\
\hline Duration of heroin use, years $( \pm S D)$ & & & $8.6 \pm 13.9$ & & & \\
\hline Last use of heroin, days $( \pm S D)$ & & & $75.0 \pm 196.1$ & & & \\
\hline Expense of heroin use at last time, NTD $( \pm S D)$ & & & $1058.8 \pm 384.6$ & & & \\
\hline Age at onset of methadone, year $( \pm S D)$ & & & $31.6 \pm 5.2$ & & & \\
\hline Duration of methadone treatment, years $( \pm S D)$ & & & $1.3 \pm 1.0$ & & & \\
\hline Last use of methadone, days $( \pm S D)$ & & & $0.5 \pm 1.2$ & & & \\
\hline Current methadone dose, $\mathrm{mg} /$ day $( \pm S D)$ & & & $37.5 \pm 21.5$ & & & \\
\hline
\end{tabular}

Notes: n, number of cases; Single included divorced, separated, or widowed; drinker means subject has used alcohol in the last 4 weeks.

Abbreviations: BMI, body mass index; HIV, human immunodeficiency virus; SD, standard deviation.

Table 2 Comparisons of Brief Symptom Rating Scale scores and health-related quality of life between heroin users and healthy controls $(n=78)$

\begin{tabular}{|c|c|c|c|c|c|}
\hline & \multirow{2}{*}{$\begin{array}{l}\text { All } \\
(n=78)\end{array}$} & \multirow{2}{*}{$\begin{array}{l}\text { Healthy controls } \\
(n=39)\end{array}$} & \multirow{2}{*}{$\begin{array}{l}\text { Heroin users } \\
(n=39)\end{array}$} & \multicolumn{2}{|c|}{ Statistics } \\
\hline & & & & $\bar{T}$ & $P$ value \\
\hline \multicolumn{6}{|l|}{ BSRS scores $( \pm S D)$} \\
\hline Somatization & $2.4 \pm 2.9$ & $1.6 \pm 1.7$ & $3.2 \pm 3.5$ & 15.465 & 0.018 \\
\hline Obsession & $1.5 \pm 2.0$ & $1.2 \pm 1.5$ & $1.9 \pm 2.3$ & 5.064 & 0.109 \\
\hline Interpersonal sensitivity & $1.3 \pm 1.7$ & $1.0 \pm 1.5$ & $1.6 \pm 1.8$ & 1.892 & 0.117 \\
\hline Hostility & $1.3 \pm 2.0$ & $0.7 \pm 1.4$ & $1.8 \pm 2.4$ & 6.771 & 0.016 \\
\hline Depression & $2.5 \pm 2.8$ & $1.6 \pm 2.2$ & $3.3 \pm 3.2$ & 7.187 & 0.008 \\
\hline Anxiety & $2.5 \pm 3.2$ & $1.6 \pm 2.2$ & $3.4 \pm 3.8$ & 11.18 & 0.013 \\
\hline Phobia & $1.2 \pm 2.1$ & $0.6 \pm 1.2$ & $1.8 \pm 2.5$ & 12.558 & 0.014 \\
\hline Paranoid & $1.3 \pm 1.6$ & $0.9 \pm 1.6$ & $1.7 \pm 1.6$ & 0.096 & 0.045 \\
\hline Addition & $1.7 \pm 1.8$ & $0.9 \pm 1.3$ & $2.4 \pm 2.0$ & 7.366 & $<0.001$ \\
\hline General symptom severity index & $16.9 \pm 18.9$ & $11.2 \pm 13.1$ & $22.7 \pm 22.1$ & 6.159 & 0.007 \\
\hline Positive symptom total number & $11.2 \pm 9.6$ & $8.0 \pm 7.8$ & $14.4 \pm 10.1$ & 4.751 & 0.003 \\
\hline Positive symptom distress index & $1.2 \pm 0.6$ & $I . I \pm 0.5$ & $1.2 \pm 0.7$ & 2.07 & 0.566 \\
\hline \multicolumn{6}{|l|}{ WHOQOL ( \pm SD) } \\
\hline Physical domain & $62.8 \pm 17.6$ & $71.0 \pm 13.6$ & $54.6 \pm 17.4$ & 3.477 & $<0.001$ \\
\hline Psychological domain & $54.4 \pm 22.4$ & $62.9 \pm 17.2$ & $46.0 \pm 23.9$ & 2.840 & 0.001 \\
\hline Social domain & $59.0 \pm 19.8$ & $65.1 \pm 17.2$ & $52.9 \pm 20.5$ & 0.450 & 0.006 \\
\hline Environmental domain & $59.3 \pm 19.3$ & $68.5 \pm 13.8$ & $50.0 \pm 19.6$ & 6.049 & $<0.001$ \\
\hline \multicolumn{6}{|l|}{ EQ-5D scores $( \pm S D)$} \\
\hline EQ-TTO & $0.9 \pm 0.2$ & $0.9( \pm 0.2)$ & $0.8( \pm 0.1)$ & 0.136 & 0.182 \\
\hline EQ-VAS & $74.0 \pm 16.4$ & $81.0( \pm 11.6)$ & $67.0( \pm 17.6)$ & 6.043 & $<0.001$ \\
\hline
\end{tabular}

Note: n, number of cases.

Abbreviations: BSRS, Brief Symptom Rating Scale; SD, standard deviation; EQ-TTO, EuroQoL-5D time-trade-off score; EQ-VAS, EuroQoL-5D score on visual analog scale. 
indices of BSRS, ie, general symptom severity index and positive symptom total number $(P=0.007$ and $P=0.003$, respectively) were higher in heroin users. As compared with healthy controls, heroin users had worse HRQoL in physical $(P<0.001)$, psychological $(P=0.001)$, social $(P=0.006)$, and environmental $(P<0.001)$ domains and also lower EuroQol-5D VAS $(P<0.001)$.

\section{Correlates of HRQoL}

For heroin users, HRQoL scores were positively correlated with male gender, higher educational level, and more days of last heroin use, and negatively correlated with age, number of comorbid diseases, hepatitis $\mathrm{C}$ viral infection, and age at onset of methadone treatment (Table 3). Self-reported psychopathology ascertained by BSRS scores was negatively correlated with HRQoL.

\section{Multiple regression analysis of HRQoL}

We found that the physical domain of HRQoL was predicted by anxiety and additional symptoms $\left(R^{2}=0.362\right)$; the psychological domain was predicted by depression $\left(R^{2}=0.324\right)$; the environmental domain was predicted by paranoid symptoms $\left(R^{2}=0.207\right)$; and the social domain, EuroQol-5D time-trade-off, and EuroQol-5D VAS were predicted by additional symptoms only $\left(R^{2}=0.170,0.323\right.$, and 0.207 , respectively, Table 4 ).

\section{Discussion}

This pilot study explored the relationships between selfreported psychopathology of comprehensive domains and HRQoL in Asian heroin users. Our results support our first hypothesis that heroin users, even when receiving methadone

Table 3 Correlates of health-related quality of life among heroin users treated with methadone $(n=39)$

\begin{tabular}{|c|c|c|c|c|c|c|}
\hline & \multicolumn{4}{|c|}{ WHO-QOL domains } & \multicolumn{2}{|c|}{ EuroQol scores } \\
\hline & $\begin{array}{l}\text { Physical } \\
\text { domain }\end{array}$ & $\begin{array}{l}\text { Psychological } \\
\text { domain }\end{array}$ & $\begin{array}{l}\text { Social } \\
\text { domain }\end{array}$ & $\begin{array}{l}\text { Environmental } \\
\text { domain }\end{array}$ & TTO & VAS \\
\hline Age & -0.256 & -0.268 & -0.254 & -0.100 & -0.085 & $-0.376^{*}$ \\
\hline Gender, female (0), male (I) & -0.096 & 0.000 & -0.047 & -0.095 & $0.391 *$ & -0.094 \\
\hline $\begin{array}{l}\text { Education, junior high school and } \\
\text { below }(0) \text {, above }(1)\end{array}$ & $0.387^{*}$ & 0.286 & 0.252 & 0.259 & 0.297 & 0.154 \\
\hline $\begin{array}{l}\text { Marital status, unmarried, divorced, separated, } \\
\text { widowed }(0) \text {, married or cohabiting (I) }\end{array}$ & 0.027 & 0.015 & 0.197 & 0.077 & -0.008 & 0.202 \\
\hline $\mathrm{BMI}, \mathrm{kg} / \mathrm{m}^{2}$ & 0.180 & 0.184 & -0.036 & 0.076 & 0.312 & 0.071 \\
\hline Smoker, no (0), yes (I) & $\mathrm{n} / \mathrm{a}$ & $\mathrm{n} / \mathrm{a}$ & $\mathrm{n} / \mathrm{a}$ & $\mathrm{n} / \mathrm{a}$ & $\mathrm{n} / \mathrm{a}$ & $\mathrm{n} / \mathrm{a}$ \\
\hline Drinker, no $(0)$, yes $(I)$ & -0.190 & -0.190 & -0.266 & -0.121 & -0.025 & -0.182 \\
\hline Number of comorbid diseases & -0.273 & -0.197 & -0.068 & -0.161 & $-0.383 *$ & -0.213 \\
\hline HIV positivity, no (0), yes (I) & -0.211 & -0.156 & -0.078 & -0.166 & 0.007 & -0.053 \\
\hline Hepatitis B, no (0), yes (I) & -0.295 & -0.276 & -0.033 & -0.123 & -0.198 & -0.133 \\
\hline Hepatitis C, no (0), yes (I) & -0.143 & -0.032 & 0.051 & 0.042 & $-0.348^{*}$ & -0.097 \\
\hline Onset of heroin use, years & -0.003 & -0.172 & -0.037 & 0.007 & -0.204 & -0.302 \\
\hline Duration of heroin use, years & 0.049 & 0.110 & -0.068 & 0.110 & 0.069 & -0.026 \\
\hline Last use of heroin, days & $0.344^{*}$ & 0.315 & 0.169 & $0.347^{*}$ & -0.025 & 0.294 \\
\hline Expense of heroin use at last time, NTD & 0.002 & 0.136 & -0.137 & 0.079 & 0.100 & -0.107 \\
\hline Age at onset of methadone, year & -0.214 & -0.284 & -0.270 & -0.124 & -0.084 & $-0.333^{*}$ \\
\hline Duration of methadone treatment, years & -0.142 & -0.015 & -0.026 & 0.128 & -0.105 & $0.13 \mid$ \\
\hline Last use of methadone, days & -0.118 & -0.139 & -0.160 & -0.072 & -0.186 & -0.223 \\
\hline Current methadone dose, mg/day & 0.025 & 0.146 & 0.034 & 0.065 & 0.005 & 0.017 \\
\hline \multicolumn{7}{|l|}{ BSRS scores } \\
\hline Somatization & $-0.415^{* *}$ & $-0.372 *$ & -0.305 & -0.271 & $-0.54 \mid * * *$ & -0.291 \\
\hline Obsession & $-0.405^{*}$ & $-0.387 *$ & $-0.349 *$ & $-0.385^{*}$ & -0.271 & -0.208 \\
\hline Interpersonal sensitivity & $-0.385^{*}$ & $-0.483 * *$ & -0.281 & $-0.439 * *$ & $-0.498 * *$ & -0.146 \\
\hline Hostility & $-0.417^{* *}$ & $-0.44 I * *$ & -0.314 & $-0.33 I^{*}$ & $-0.554 * * *$ & -0.183 \\
\hline Depression & $-0.509 * *$ & $-0.492 * *$ & $-0.356^{*}$ & $-0.442 * *$ & $-0.542 * * *$ & $-0.349 *$ \\
\hline Anxiety & $-0.519 * *$ & $-0.482 * *$ & $-0.381 *$ & $-0.459 * *$ & $-0.550 * * *$ & -0.306 \\
\hline Phobia & $-0.368^{*}$ & $-0.449 * *$ & $-0.333^{*}$ & $-0.384^{*}$ & $-0.395^{*}$ & -0.183 \\
\hline Paranoid & $-0.484^{* *}$ & $-0.465^{* *}$ & $-0.356 *$ & $-0.506 * *$ & $-0.443 * *$ & -0.233 \\
\hline Addition & $-0.523^{* *}$ & $-0.485^{* *}$ & $-0.450 * *$ & $-0.334^{*}$ & $-0.6 \mathrm{II} * * *$ & $-0.417^{* *}$ \\
\hline
\end{tabular}

Notes: $* P<0.05 ; * * P<0.01$; $* * * P<0.001$. Drinker means the subject has used alcohol in the last 4 weeks.

Abbreviations: BMI, body mass index; BSRS, Brief Symptom Rating Scale; EQ-TTO, EuroQoL-5D time-trade-off score; EQ-VAS, EuroQoL-5D score on visual analog scale; NTD, New Taiwan dollars. 
Table 4 Predictors of health-related quality of life among heroin users treated with methadone $(n=39)$

\begin{tabular}{|c|c|c|c|c|c|c|}
\hline & \multicolumn{4}{|c|}{ WHO-QOL domain scores } & \multicolumn{2}{|c|}{ EuroQol-5D scores } \\
\hline & $\begin{array}{l}\text { Physical } \\
\text { domain }\end{array}$ & $\begin{array}{l}\text { Psychological } \\
\text { domain }\end{array}$ & $\begin{array}{l}\text { Social } \\
\text { domain }\end{array}$ & $\begin{array}{l}\text { Environmental } \\
\text { domain }\end{array}$ & TTO & VAS \\
\hline & $R^{2}=0.362$ & $R^{2}=0.324$ & $R^{2}=0.170$ & $R^{2}=0.207$ & $R^{2}=0.323$ & $R^{2}=0.207$ \\
\hline BSRS scores & \multicolumn{6}{|c|}{ Standardized coefficient $(\beta)$} \\
\hline Depression & $\mathrm{n} / \mathrm{a}$ & $-0.577^{* * *}$ & $\mathrm{n} / \mathrm{a}$ & $\mathrm{n} / \mathrm{a}$ & $\mathrm{n} / \mathrm{a}$ & $\mathrm{n} / \mathrm{a}$ \\
\hline Anxiety & $-0.29 I^{*}$ & $\mathrm{n} / \mathrm{a}$ & $\mathrm{n} / \mathrm{a}$ & $\mathrm{n} / \mathrm{a}$ & $\mathrm{n} / \mathrm{a}$ & $\mathrm{n} / \mathrm{a}$ \\
\hline Paranoid & $\mathrm{n} / \mathrm{a}$ & $\mathrm{n} / \mathrm{a}$ & $\mathrm{n} / \mathrm{a}$ & $-0.466 * * *$ & $\mathrm{n} / \mathrm{a}$ & $\mathrm{n} / \mathrm{a}$ \\
\hline Addition & $-0.378 * *$ & $\mathrm{n} / \mathrm{a}$ & $-0.426 * * *$ & $\mathrm{n} / \mathrm{a}$ & $-0.576 * * *$ & $-0.466 * * *$ \\
\hline
\end{tabular}

Notes: $* P<0.05 ; * * P<0.01$; ***P $<0.001$.

Abbreviations: BSRS, Brief Symptom Rating Scale; TTO, time-trade-off score; VAS, visual analog scale score; n/a, not available.

treatment, still have worse HRQoL and more self-reported psychopathology than healthy controls. We also found that comorbid psychopathology in heroin users, such as anxiety, depression, paranoia, and additional symptoms (ie, poor appetite, sleep difficulty), independently predicted reduced HRQoL in different domains. Thus, our second hypothesis was also validated.

Our results show that heroin users treated with methadone have more psychopathology than healthy controls, including more somatization, hostility, depression, anxiety, phobia, paranoia, and additional symptoms. This is consistent with a previous report. ${ }^{5}$ Grau et al used a semistructured interview with heroin abusers, and found that past history of opioid overdose had the strongest correlation with a higher somatization subscale score. ${ }^{26}$ However, unlike in our study, they did not measure comorbid physical illness, which may be related to somatization. The prior literature also indicates the role of hostility in predicting opioid abuse. ${ }^{27}$ In comparison, BSRS scales for both groups in our research did not differ in obsession, interpersonal sensitivity, and positive symptom distress index.

In our study, comorbid use of tobacco and alcohol was more prevalent among heroin users on methadone treatment than in healthy controls. However, use of alcohol was not correlated with poor HRQoL in any of the domains of the WHOQoL and EuroQol-5D. The existing literature shows that methadone maintenance treatment has limited effects on alcohol abstinence among heroin users. ${ }^{12}$ Treatment aimed at reducing tobacco and alcohol use is still necessary.

Our results confirm that heroin users treated with methadone have significantly lower HRQoL in all domains (physical, psychological, social, environmental) of the WHOQOL and EuroQol-5D VAS than healthy controls, which was in line with previous studies. ${ }^{5,15}$ In a review by González-Saiz et al, opiate users had poorer HRQoL in most Short Form-36 dimensions (role limitation due to physical problems, bodily pain, general health, vitality, social functioning, emotional problems, and mental health) except for physical functioning, as compared with patients having minor physical problems. Analysis of published studies using the Multidimensional Index of Quality of Life shows that drug abusers have worse HRQoL than patients with cardiovascular disease in all dimensions, except for physical functioning and physical health. ${ }^{15}$

The environmental domain of HRQoL has been less well discussed. In our study, we found that heroin users treated with methadone had worse HRQoL in the environmental domain of the WHOQOL-BREF, which includes the following items: financial resources; freedom, physical safety, and security; health and social care, and its accessibility and quality; home environment; opportunities for acquiring new information and skills; participation in and opportunities for recreation/leisure activities; physical environment (pollution/ noise/traffic/climate); and transport. ${ }^{22}$ To improve the effectiveness of a methadone maintenance treatment program, it is mandatory to improve the environmental domain of heroin users at the public health level. Targeting ancillary psychosocial services which focus on legal, educational, vocational, recreational, financial, and family issues, as well as interpersonal difficulties, would be beneficial for this population. ${ }^{28}$ In comparison, Yen et al found that use of heroin had a negative impact in all WHOQOL-BREF domains (physical, psychological, social relationships) except for the environmental domain in another Taiwanese population..$^{18}$ In fact, our participants, who were recruited from Yunlin County, an agricultural area in Taiwan, tended to have a relatively worse financial status than those in the study done by Yen et al in Tainan County. Hence, poorer HRQoL in the environmental domain might be related to poor finance-related conditions in our participants.

Self-reported psychopathology on the BSRS independently predicted reduced HRQoL in heroin users. We found 
that predictors of HRQoL included additional symptoms, depression, anxiety and paranoia. Additional symptoms on BSRS refers to poor appetite and sleep difficulty. Poor appetite and sleep difficulty are common symptoms and very highly prevalent in heroin users. ${ }^{29,30}$ Short sleep duration ( $<6$ hours) is associated with poor physical and self-perceived mental health status, as well as increased morbidity and mortality. ${ }^{31,32}$ The association between additional symptoms on the BSRS and poor HRQoL in heroin users warrants clinical intervention. The association between depression, anxiety, and lower HRQoL in heroin users treated with methadone has been reported. ${ }^{5}$ In the published literature, heroin users with depression are reported to have poorer HRQoL than those without depression. ${ }^{18}$ They also have a higher risk of anxiety disorders than other drug users, while anxiety has a substantial influence on HRQoL. ${ }^{33,34}$ A previous study showed that both depression and paranoid symptoms based on the Symptom Checklist-90 were the main symptoms in heroin users treated with methadone. ${ }^{35}$ Clinicians should monitor for additional symptoms, as well as depression, anxiety, and paranoia to improve HRQoL in heroin users. Consequently, a comprehensive treatment model for heroin misuse could attempt to explore and ameliorate the subjective sense of psychological distress in addition to objective measures. ${ }^{17}$

There are some limitations to this study. First, the majority of our participants were males and of Chinese ethnicity $(84.6 \%)$, so there is some concern as to whether these findings could be generalized to women and other ethnicities. The National Drug Abuse Treatment Clinical Trials Network (CTN001-002) reported that, in the US, female and white opioid-dependent persons may have more psychiatric symptoms, more family/social relationship problems, and poorer HRQoL than males and African Americans. ${ }^{36}$ Gender and ethnic differences might play a role in the HRQoL of heroin users. Future research should be focused on the probable moderating role of gender differences in the association between psychopathology and HRQoL in heroin users. Second, our heroin users were recruited from a methadone clinic and so are not representative of street drug users. We designed this study to investigate outpatients who were participants in a methadone maintenance treatment. From our study results, we can decide on methods to improve the quality of methadone maintenance treatment, but further studies should be directed towards comparison of patients receiving methadone maintenance treatment and those who are not, so that we can determine the impact of methadone on HRQoL in street heroin users. Third, the cross-sectional design of our study is unable to make causal inferences. Prospective studies will be needed to determine any dynamic process between self-reported psychopathology and HRQoL. Fourth, multiple comparisons in $t$-testing between two groups may raise the statistical problem of familywise error rate, so this is also a limitation in our study.

In conclusion, HRQoL provides valuable and important information about heroin users on methadone treatment. ${ }^{14}$ Our results show that self-reported psychopathology, including depression, anxiety, paranoia, and additional symptoms, have a negative impact on HRQoL in Asian heroin users treated with methadone. In addition to harm reduction and devising an abstinence program, a treatment model for comorbid psychopathology is of crucial importance to improve HRQoL in this population. We recommend that HRQoL and self-reported psychopathology should be routinely evaluated in comprehensive treatment programs for heroin abusers.

\section{Acknowledgments}

This study was supported by a grant from the National Taiwan University Hospital, Yun-Lin Branch (NTUHYL.99 N015). We thank Wei J Chen, Jung-Der Wang, Hsin-Yi Lee, and Grace Yao for their permission to use the questionnaires.

\section{Disclosure}

The authors report no conflicts of interests in this work.

\section{References}

1. Chang LR, Lin YH, Kuo TB, et al. Cardiac autonomic modulation during methadone therapy among heroin users: a pilot study. Prog Neuropsychopharmacol Biol Psychiatry. 2012;37:188-193.

2. McLellan AT, Lewis DC, O'Brien CP, Kleber HD. Drug dependence, a chronic medical illness: implications for treatment, insurance, and outcomes evaluation. JAMA. 2000;284:1689-1695.

3. Millson PE, Challacombe L, Villeneuve PJ, et al. Self-perceived health among Canadian opiate users: a comparison to the general population and to other chronic disease populations. Can J Public Health 2004;95:99-103.

4. Huang WL, Lin YH, Kuo TB, Chang LR, Chen YZ, Yang CC. Methadone-mediated autonomic functioning of male patients with heroin dependence: the influence of borderline personality pattern. PLoS One. 2012;7:e37464.

5. Carpentier PJ, Krabbe PF, van Gogh MT, Knapen LJ, Buitelaar JK, de Jong CA. Psychiatric comorbidity reduces quality of life in chronic methadone maintained patients. Am J Addict. 2009;18:470-480.

6. Reimer J, Verthein U, Karow A, Schafer I, Naber D, Haasen C. Physical and mental health in severe opioid-dependent patients within a randomised controlled maintenance treatment trial. Addiction. 2011; 106:1647-1655.

7. Schwartz RP, Highfield DA, Jaffe JH, et al. A randomized controlled trial of interim methadone maintenance. Arch Gen Psychiatry. 2006;63: 102-109.

8. Marsch LA. The efficacy of methadone maintenance interventions in reducing illicit opiate use, HIV risk behavior and criminality: a meta-analysis. Addiction. 1998;93:515-532. 
9. Gibson A, Degenhardt L, Mattick RP, Ali R, White J, O’Brien S. Exposure to opioid maintenance treatment reduces long-term mortality. Addiction. 2008;103:462-468.

10. Pedro Ruiz ECS. Substance Abuse: A Comprehensive Textbook. 5th ed. Philidelphia, PA: Lippincott Williams \& Wilkins; 2011.

11. Stitzer ML, Iguchi MY, Felch LJ. Contingent take-home incentive: effects on drug use of methadone maintenance patients. J Consult Clin Psychol. 1992;60:927-934.

12. King VL, Kidorf MS, Stoller KB, Schwartz R, Kolodner K, Brooner RK. A 12-month controlled trial of methadone medical maintenance integrated into an adaptive treatment model. J Subst Abuse Treat. 2006;31:385-393.

13. Winstock AR, Lea T, Sheridan J. Prevalence of diversion and injection of methadone and buprenorphine among clients receiving opioid treatment at community pharmacies in New South Wales, Australia. Int J Drug Policy. 2008;19:450-458.

14. Karow A, Verthein U, Pukrop R, et al. Quality of life profiles and changes in the course of maintenance treatment among 1,015 patients with severe opioid dependence. Subst Use Misuse. 2011;46: 705-715.

15. Gonzalez-Saiz F, Rojas OL, Castillo II. Measuring the impact of psychoactive substance on health-related quality of life: an update. Curr Drug Abuse Rev. 2009;2:5-10.

16. Peles E, Schreiber S, Naumovsky Y, Adelson M. Depression in methadone maintenance treatment patients: rate and risk factors. $J$ Affect Disord. 2007;99:213-220.

17. Lasalvia A, Ruggeri M, Santolini N. Subjective quality of life: its relationship with clinician-rated and patient-rated psychopathology. The South-Verona Outcome Project 6. Psychother Psychosom. 2002;71: 275-284.

18. Yen CN, Wang CS, Wang TY, Chen HF, Chang HC. Quality of life and its correlates among heroin users in Taiwan. Kaohsiung J Med Sci. 2011;27:177-183.

19. Derogatis LR. Rickels K RA. The SCL-90 and the MMPI:a step in the validation of a new self-report scale. The British Journal of Psychiatry. 1976;128:280-289.

20. Lee MB, Lee YJ, Yen LL, Lin MH, Lue BH. Reliability and validity of using a Brief Psychiatric Symptom Rating Scale in clinical practice. J Formos Med Assoc. 1990;89:1081-1087.

21. Chen CA, Liao SC, Wang JK, et al. Quality of life in adults with congenital heart disease: biopsychosocial determinants and sex-related differences. Heart. 2011;97:38-43.

22. Group TW. Development of the World Health Organization WHOQOLBREF quality of life assessment. Psychol Med. 1998;28:551-558.

23. Yao G, Chung CW, Yu CF, Wang JD. Development and verification of validity and reliability of the WHOQOL-BREF Taiwan version. J Formos Med Assoc. 2002;101:342-351.
24. Chang LR, Lin YH, Kuo TB, et al. Autonomic modulation and healthrelated quality of life among schizophrenic patients treated with nonintensive case management. PLoS One. 2011;6:e26378.

25. Chang TJ, Tarn YH, Hsieh CL, Liou WS, Shaw JW, Chiou XG. Taiwanese version of the EQ-5D: validation in a representative sample of the Taiwanese population. J Formos Med Assoc. 2007;106:1023-1031.

26. Grau LE, Green TC, Torban M, et al. Psychosocial and contextual correlates of opioid overdose risk among drug users in St Petersburg, Russia. Harm Reduct J. 2009;6:17.

27. Walter D, Nagoshi C, Muntaner C, Haertzen CA. The prediction of drug dependence from expectancy for hostility while intoxicated. Int J Addict. 1990;25:1151-1168.

28. McLellan AT, Arndt IO, Metzger DS, Woody GE, O'Brien CP. The effects of psychosocial services in substance abuse treatment. JAMA. 1993;269:1953-1959.

29. Kanof PD, Aronson MJ, Ness R. Organic mood syndrome associated with detoxification from methadone maintenance. Am J Psychiatry. $1993 ; 150: 423-428$.

30. Stein MD, Kurth ME, Sharkey KM, Anderson BJ, Corso RP, Millman RP. Trazodone for sleep disturbance during methadone maintenance: a double-blind, placebo-controlled trial. Drug Alcohol Depend. 2012;120:65-73.

31. Franco OH, Wong YL, Kandala NB, et al. Cross-cultural comparison of correlates of quality of life and health status: the Whitehall II Study (UK) and the Western New York Health Study (US). Eur J Epidemiol. 2012;27:255-265

32. Stranges S, Dorn JM, Shipley MJ, et al. Correlates of short and long sleep duration: a cross-cultural comparison between the United Kingdom and the United States: the Whitehall II Study and the Western New York Health Study. Am J Epidemiol. 2008;168:1353-1364.

33. Lejuez CW, Paulson A, Daughters SB, Bornovalova MA, Zvolensky MJ. The association between heroin use and anxiety sensitivity among inner-city individuals in residential drug use treatment. Behav Res Ther. 2006;44:667-677.

34. Frischknecht U, Beckmann B, Heinrich M, et al. The vicious circle of perceived stigmatization, depressiveness, anxiety, and low quality of life in substituted heroin addicts. Eur Addict Res. 2011;17:241-249.

35. Jacobs PE, Doft EB, Koger J. A study of SCL-90 scores of 264 methadone patients in treatment. Int J Addict. 1981;16:541-548.

36. Wu LT, Ling W, Burchett B, Blazer DG, Shostak J, Woody GE. Gender and racial/ethnic differences in addiction severity, HIV risk, and quality of life among adults in opioid detoxification: results from the National Drug Abuse Treatment Clinical Trials Network. Subst Abuse Rehabil. 2010:13-22.
Neuropsychiatric Disease and Treatment

\section{Publish your work in this journal}

Neuropsychiatric Disease and Treatment is an international, peerreviewed journal of clinical therapeutics and pharmacology focusing on concise rapid reporting of clinical or pre-clinical studies on a range of neuropsychiatric and neurological disorders. This journal is indexed on PubMed Central, the 'PsycINFO' database and CAS.

\section{Dovepress}

The manuscript management system is completely online and includes a very quick and fair peer-review system, which is all easy to use. Visit http://www.dovepress.com/testimonials.php to read real quotes from published authors. 